\title{
A study about external communication of construction firms
}

\author{
A.E. Keleş ${ }^{1 *}$, M.E. Öcal ${ }^{2}$ \\ ${ }^{1}$ Adana Science and Technology University, Department of Civil Engineering, Adana, Turkey \\ ${ }^{2}$ Osmaniye Korkut Ata University, Department of Civil Engineering, Osmaniye, Turkey
}

\begin{abstract}
In today the importance of communication in the construction industry in the world is not known enough. Therefore, various defects are experienced in business processes. This is also valid for the construction industry. Losses due to lack of communication is an issue that is overlooked in the construction business. In this study, the construction and operating business to create awareness about the importance of communication and place of origin proposals have been made to minimize problems. In this respect firstly, communication problems in the construction sector were discussed. It is divided into internal and external business communication. In this study, it has been developed solutions to the construction firm's external communication. External communication stakeholders in the construction sector are defined and the communications of the enterprises with these stakeholders have been examined. The economic dimension of the problem that occurred communication origin were also discussed. It has been argued that communicationrelated problems have lost to business economies.
\end{abstract}

\section{Keywords}

Construction communication; Construction external communication; Communication methods, Construction firms; Communication problems

Received: 03 December 2018; Accepted: 24 December 2018

ISSN: 2630-5771 (online) @ 2018 Golden Light Publishing All rights reserved.

\section{Introduction}

In order to continue the life cycle, people have to live and work with others. In this regard, the concept of communication emerges as a natural consequence of the social life. Business life directly affects human behavior and all kinds of behaviors exhibited by individuals directly affect productivity in business life. From these perspectives, it has seen that communication is interwoven with many issues related to management in business life.

In this study, it was aimed to minimize the problems in communication with non-business stakeholders, in which every construction operation is in contact regardless of scale, by taking non-business communication into consideration. Although the issue has started to draw attention in recent years, the number of researchers doing research in our country is small todays.

\subsection{The concept of communication}

There are various definitions of communication concept in the literature. Communication in today's scientific studies is a two-way process. When the types of communication are examined, the three main headlines come out. These are nonverbal communication, verbal communication and written communication as shown in Fig. 1. It is also an evident that communication has a vital importance

\footnotetext{
* Corresponding author

Email: aekeles@adanabtu.edu.tr
} 


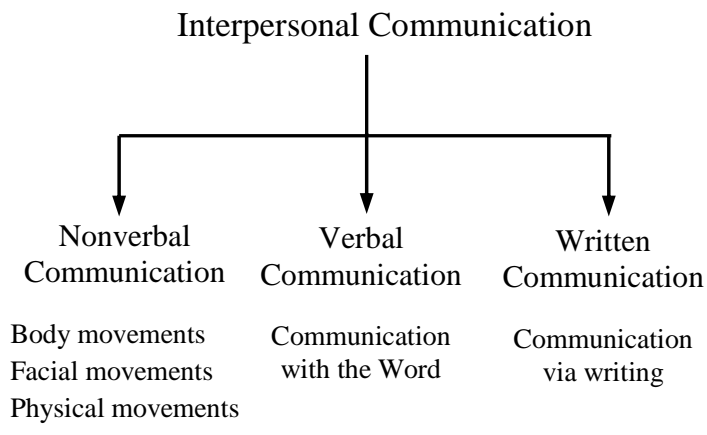

Fig. 1. Types of interpersonal communication

to all businesses, since people have a combination of these three styles in their work lives. The figure showing the types of interpersonal communication is shown in Fig. 1.

\section{Construction communication}

Communication in the construction sector has been particularly interested in lots of researchers in recent years. This process, which was realized only in corporate enterprises some years ago, is today one of the basic business functions. Communication is a fundamental element in all other types of businesses, as well as in construction companies, where managers and managers can make the right decisions and pass them on. Regardless of the structural size of the construction companies and the type of work they do, it is important that the communication processes are carried out consciously and well at all stages from the design stage of the structures to the projecting, application and supervision stages.

Communication about construction organization in some studies; it is divided into formal and informal communication with its main directions in the design phase and it is stated that there are differences between the communication modes and systems in development and production stages [1, 2, 3].

Assuming communication in the construction industry is not interrupted, it is doubtless that management can turn into a complexity. When this happens, subordinates will not clearly know what is desired of them, employees will not be able to provide coordination among them, and business management will become chaotic [4].

Effective communication process is essential for the success of construction projects. Previous research shows that construction project teams spend majority of their time communicating with other parties and stakeholders. However, only few previous studies address project-level communication process in construction, in particular, from a project management perspective. This idea is highlighted in this study [5].

A research finding that communication is needed to effectively communicate the areas of cost, scope and time, and quality, which are the results of the interrelationship between scope, cost and time. Communication is the function that integrates cost, scope and time to achieve a quality product and may be seen as having a foundation function [6].

Another study empirically examined the communication capabilities for green supply chain management and the relationship among external green integration, green cost reduction, and corporate competitiveness from the suppliers' perspective. The findings from this study indicated that suppliers with higher information sharing capabilities improved their environmental collaboration, contributed to green cost reduction, and achieved their competitive advantage [7].

Information and communication technology has had large effects on the development of architecture, engineering and construction organizations in past decades. The effects have resonated in various disciplines such as communication approach and employee behavior. The study examined the relationship between these disciplines [8].

\section{Materials and methods}

The research emphasizes the importance of communication in construction companies. In this study, a situation analysis was made about this issue that was felt in our country especially, and at the same time, communication problems were detected by face to face interviews with sector representatives. After the interviews with 
construction firms authorities, it was determined what problems were experienced with the stakeholders. In the study, problems related to external factors that help construction companies' activities were identified and solution proposals were developed.

The data of the study were obtained by interviewing the managers of about 50 firms with working construction sector in Adana. It is presented in the related thesis [4].

\subsection{External communication stakeholders of construction firms}

In the construction sector, many different industries and working groups are in contact with each other. This leads to the formation and use of various communication systems in order to form different communication networks. For this reason, it is almost impossible to define a single communication network in which individuals working in construction companies communicate with employees who work in and out of the enterprise. However, it requires the non-business communication of the construction companies to be systematic. Otherwise, irregular and unplanned forms of communication sometimes cause disruptions and clogs in business processes, even if not otherwise noticed. Relevant situation loses material value, time, reputation and trust to businesses.

Despite all the different factors such as commercial structure, capital, number of employees, work type, the most common constructions that all construction companies contact in external communication are presented below:

- Communication with the employer

- Communication with technical staff

- Communication with accounting department

- Communication with sub-contractors

- Communication with the control mechanisms

- Communication with official institutions and organizations

- Communication with suppliers
- Communication with other organizations related to the sector

- Communication with customers

\section{Results and discussion}

In the construction sector, communication with external stakeholders often results in problems arising from misunderstanding and lack of consideration of communication, resulting in disruption of business processes or failure to achieve the desired success in projects, which causes financial losses to businesses. Establishments in which almost every construction operation is contacted in external communication have been determined, and communication troubles are presented in this section.

\subsection{Communication with the employer}

It is necessary to communicate with the land owner or the institution, if the project that the construction companies are considering is not owned by the production area. In such cases, when the requests and expectations of the parties are overlapped, the relationship with the contract is transformed into official. In this process, a two-way communication occurs between the construction company and the employer, and if this is not properly managed, various problems arise.

\subsection{Communication with the employer}

Where construction services provide services for the design of related projects from outside the enterprise, communications between these individuals and institutions should be provided on a regular basis. Relevant persons and institutions should be brought together by the construction company at certain intervals to exchange information, documents and ideas between them.

\subsection{Communication with accounting department}

In this communication style, documents such as delivery notes and invoices received from the construction site, subcontractor and suppliers must be paired and matched, and filed according to the date order, and shared with the accounting in a 
timely manner. At the same time, it is also important for the business management to meet and exchange information with the accounting unit at certain intervals.

\subsection{Communication with sub-contractors}

In such cases, many of the subcontractors who work with the business are experiencing many communication-related problems. These problems arise from the fact that the general interested parties do not use written communication from the types of communication. In order to overcome these and similar problems, the contract must be made a habit in communication between the enterprise and these organizations, and at the same time, these contracts must be in a comprehensive, detailed and concrete manner.

\subsection{Communication with the control mechanisms}

A continuous and uninterrupted communication system should be adopted at every stage of the work between construction companies and supervisory personnel. Supervise construction worker employees; that it is a phenomenon involving all the processes of work and that it is not a control of the final product at the same time but a whole activity which means that the problems or possible problems to be identified are identified and intervened without the whole being produced.

\subsection{Communication with official institutions and organizations}

Construction firms are in constant communication with the various official institutions and organizations of the other countries in the projects of the country, province, province, or international scale that are found in all processes of the projects. Here, official institutions and organizations are most commonly referred to as; Governments, municipalities, social insurance institutions, water and sewerage administrations, electricity distribution companies, civil defense and fire brigade.

\subsection{Communication with suppliers}

In today's competitive and constantly renewed market environment of construction enterprises; it is necessary to create a systematic way to eliminate the randomness in the selection and management of the suppliers in order to increase the customer satisfaction, to ensure the continuous satisfaction of the work satisfaction and the work quality.

\subsection{Communication with other organizations related to the sector}

Universities, as well as the technical departments and faculties of the sector such as construction, architecture, machinery, electricity-electronics, geology; business, economics, finance, communication and social departments such as communication and network should be important to establish. In addition, construction companies should establish an uninterrupted and regular communication network with the professional chambers to follow developments and innovations related to administrative and technical issues.

\subsection{Communication with customers}

Customer communication includes many topics such as marketing, target group creation management, sales management, sponsorship services, customer service, and many other concepts and management systems. Marketing; activities such as analysis of customer behavior, determination of the target group around the project where the project is carried out, arrangement of campaigns, realization of advertising activities to provide direct access to customers and management of orientation should be carried out. In most organizations in the sector was emphasized that the amateur approach in organization management.

\section{Conclusions}

When the literature is examined, there are few studies on "communication in the construction sector", "communication in the construction industry" and so on, despite the fact that there are many studies in social sciences in "communication", "communication in enterprises" 
and the like. It was determined that the first work of foreign origin on the subject was realized with a report to a public institution in England in 1944, followed by various studies in the following years. This clearly shows the difference; today, especially in institutionalized circles, the topic of communication which is accepted as one of the management functions of our country is a concept which cannot be realized in the construction sector.

Due to the interdependence of many different disciplines in the construction sector, the existence of diverse and complex communication networks among these disciplines makes it almost impossible to develop a single template system in terms of construction management communications. For this reason, in this study, it was aimed to determine the existing communication problems between the construction companies and the individuals, institutions and organizations with which they are in contact with the non - business liaison and to provide suggestions for their solutions and contribute to the development of non-business communication.

As a result of the study, as also it highlighted the literature, there are many problems in the construction industry that are unaware of communication angles. With this study, it has been emphasized that the subject of communication is a managerial function which should be more rigorous in the management of the companies.

\section{References}

[1] Mackinder, M., Marvin, H. Design: Decision Making in Architectural Practice. In BRE Information Paper, United Kingdom, 1982.

[2] Pietroforte, R. Communication and Information in the Building Delivery Process. PhD Thesis, Massachusetts Institute of Technology, 1992.

[3] Hill, C. J. Communication on construction sites, Proceedings of 11th Annual Conference of Association of Researchers in Construction Management, University of York, United Kingdom, 1995.

[4] Keleş, A. E. A System Proposal Which Improving Efficiency of Internal and External Communications Interest to Construction Firms.
MSc Thesis, Çukurova University Institute of Natural and Applied Sciences, 2011.

[5] Senaratne, S., Ruwanpura, M. Communication in construction: a management perspective through case studies in Sri Lanka, Architectural Engineering and Design Management 12:1(2016) 3-18.

[6] Zulch, BG. Communication: The foundation of project management. Procedia Technology 16 (2014) 1000-1009.

[7] Woo, C., Kim, M. G., Chung, Y., Rho, J. J. Suppliers' communication capability and external green integration for green and financial performance in Korean construction industry. Journal of Cleaner Production 112:1 (2016) 483493.

[8] Lu, Y., Li Y., Skibniewski, M., Wu, Z., Wang, R., Le, Y. Information and communication technology applications in architecture, engineering and construction organizations: a 15-year review. Journal of Management in Engineering 31:1 (2015). 